\title{
Research on the Estimation of the Optimum Industrial Structure in Fuzhou
}

\author{
Guotie Chen \\ College of Management, Fujian University of Technology, Xueyuan Road, Fuzhou, China
}

Keywords: Fuzhou city; The three industries; Optimal industrial structure; Optimal convergence rate

\begin{abstract}
This paper defined the meaning of the optimal industrial structure, established the endogenous growth model, and constructed the optimal growth path and convergence rate formula of the three industries. This paper estimated the optimal industrial structure of Fuzhou from 1989 to 2018, which is a developed coastal city in China. The results showed that the real growth rate and the optimal convergence rate of each industry maintained a certain relationship of the same direction, and there is also a significant gap between them in different periods. There were correlations and convergence changes between the real growth rate and the optimal convergence rate of the three industries in Fuzhou. It can clearly reflect the three industrial restructuring policies and the in-depth development of economic reform in Fuzhou, which began in the 1990s.
\end{abstract}

\section{Introduction}

In the current literature, most scholars' research on the optimal industrial structure was based on the analysis of the high-level and rationalization of industrial structure. Dasgupta and Stiglitz [1] holded that market structure and technological innovation determined industrial structure at the same time. Cohen [2] believed that the development direction of industrial structure tended to be endogenous in market concentration. Syrquin [3] analyzed the causes of industrial structure changes and further explored the root causes of economic growth. Michael Peneder [4] used empirical methods to study the impact of industrial structure on the total income and economic growth of the national economy. Vittorio Valli and Donatella Saccone [5] argued that there were two driving forces for national economic growth, the improvement of labor productivity within the industry and the redistribution of resources in industries.

\section{Manuscript Preparation}

We found that only a few scholars kept trying to study the optimal industrial structure from another perspective. For example, researchers directly quantitatively analyzed the optimal industrial structure by optimizing motivation and market equilibrium from producers and consumers. Chinese scholars Xiao Xingzhi, Peng Yizhong and Li Shaolin [6] believed that the optimal industrial structure could achieve the following objectives at the same time. Firstly, all industries allocate production factors sufficiently and effectively in the production process. Secondly, the demand and usage of production requirements of each industry have reached the maximum required by the profit maximization goal. Thirdly, the output chosen by each industry can maximize its profits. Fourth, the representative actors arrange the consumption and investment of each product according to the principle of maximizing cross-term utility. Fifthly, there is no surplus in the output of each industry after it is used for consumption and reproduction. Their contribution was to develop a theoretical model that could be tested and applied by empirical evidence and could well describe the optimal growth path of the three industries in China.

We also found that there were some limitations in previous research. Firstly, most of the models to discuss the endogenous problem of industrial structure remained at the theoretical level, and it was difficult to use them effectively in empirical research. Secondly, empirical studies related to industrial structure were basically limited to revealing the relationship between industrial structure and other economic variables, such as the relationship between industrial structure and economic 
growth, economic fluctuation and economic cycle. Thirdly, Some studies use some subjective knowledge as implicit premise to describe the level of industrial structure optimization by constructing statistical indicators. For example, it was the better and the higher for the proportion of service industry and high value-added processing industry. Fourthly, only two-period discrete model equilibrium had been established by scholars who adopted the equilibrium direct research method. According to Xiao Xingzhi's [6] standpoint, we extend the model to a continuous and infinite period to obtain the optimal growth path and convergence rate of the three industries. In this paper, the optimal convergence rate of economic growth was used to calculate the three industrial structures of Fuzhou. We calculated by the following specific parameters: labor output elasticity, population growth rate, subjective utility discount factor and risk aversion factor.

\section{Theoretical Model}

\subsection{The meaning and classification of industrial structure}

Industrial structure refers to the composition, connection and proportional relationship of the three industries. Industrial structure plays an important role in the national economy, which is closely related to economic growth, economic cycle and resource utilization. The composition, connection and proportion of each industrial sector are different, and their contribution to the economy is also different. In economic research, according to the classification of three industries, it can be divided into primary industry, secondary industry and tertiary industry from the perspective of historical development sequence of social production activities. Primary industry refers to agriculture, including planting, forestry, woodworking and fishery. Secondary industry refers to industry and construction business, and industry includes digging, manufacture, production and supply of power, gas and water. The tertiary industry refers to other industries besides the primary industry and the secondary industry, mainly the service industry. This paper used the three-industry classification method to study.

\subsection{Definition of optimal industrial structure}

This paper defined that the optimal industrial structure could achieve the following four goals at the same time. Firstly, all industries have fully and effectively allocated production factors in the process of production. Secondly, representative consumers arrange the consumption and investment of each product according to the principle of maximizing cross-term utility, which means that there is no excessive consumption and no excessive investment in society in the process of consumption. Thirdly, each industry has achieved its goal of maximizing its profits, and at this time, employment and output have also been maximized. Fourthly, all industries have reached a balanced state. There is no surplus of output after it is used for consumption and investment. The total savings of microindividuals equals the total investment demand of the whole society.

\subsection{Theoretical model of optimal industrial structure}

\subsubsection{Maximizing producer profit}

This paper used the three-industry classification method to research, namely, the division of the primary industry, the secondary industry and the tertiary industry. In research, the production process of each industry can be abstracted as the corresponding production function, but the difference of production function can be expressed by different parameters. Each parameter represents a feature of the production function. This paper assumed that the production functions of all industries obey the Cobb-Douglas form, and producers produce through labor and capital. We distinguished three industries - agriculture, industry and service industries according to the degree of difference between ${ }^{\alpha}$ and $\mathrm{A}$ in the production function. Every industry is regarded as an independent decision-making unit, which carries out optimal demand and allocation based on the principle of profit maximization. According to Xiao Xingzhi,'s [6] standpoint, supposing that the production function models of the primary industry, secondary industry and tertiary industry are as 
follows: $Y_{i}=A_{i} L_{i}^{a_{i}} K_{i}^{1-a_{i}}(i=1,2,3)$. The producer should choose how much capital and labor to invest and how much output to maximize his own profits, that is:

$$
\max _{k_{i} l_{i}} \pi_{i}=P_{i} Y_{i}-R_{i} K_{i}-W_{i} L_{i}
$$

Meanwhile, per capital output and per capita capital stock are defined respectively.

$$
Y_{i}=\frac{Y_{i}}{L_{i}}, k_{i}=K_{i} / L_{i}
$$

Thus, the optima condition (F.O.C.) can be obtained as follows:

$$
\left\{\begin{array}{l}
\frac{\partial \pi_{i}}{\partial K_{i}}=\left(P_{i}+Y_{i} P_{i}^{\prime}\right) M P K_{i}-R_{i}=0 \\
\frac{\partial \pi_{i}}{\partial L_{i}}=\left(P_{i}+Y_{i} P_{i}^{\prime}\right) M P L_{i}-W_{i}=0
\end{array}\right.
$$

Where $R_{\tilde{i}}$ is the nominal price of capital, $W_{i}$ is the nominal price of labor force.

The real capital price is defined as: $\gamma_{i t}=R_{i t} /\left(1-N_{i t}\right) P_{i t}$

The real wage is defined as: $\omega_{i t}=W_{i t} /\left(1-N_{i t}\right) P_{i t}$

It can be obtained that:

$$
\left\{\begin{array}{c}
\gamma_{i t}=M P K_{i}=f^{\prime}\left(k_{i t}\right) \\
\omega_{i t}=M P L_{i}=f^{\prime}\left(k_{i t}\right)-f^{\prime}\left(k_{i t}\right) k_{i t}
\end{array}\right.
$$

Use 12-point type for the subtitle, aligned to the left, line space exactly is single with bold font style.

Words like "is", “or", "then”, etc. should not be capitalized unless they are the first word of the subtitle. The initial letters should be capitalized. No formulas or special characters of any form or language are allowed in the subtitle.

\subsubsection{Maximizing consumer utility}

Regarding each industry as a separate economy, a single main body is both producer and consumer in each economy. According to Xiao Xingzhi,'s (2012) [6]standpoint, this paper studies the cross-period consumption behavior of representative consumers in order to maximize their utility continuously and indefinitely. Assuming that the discount rate is a positive constant, $0<\rho<1$, the discount of all consumer utility can be expressed as $U_{i}=\int_{U}^{\infty}\left(C_{i}\right) e^{-p_{i} t} d t$. Demand is the lasting driving force of economic growth. The ultimate goal of economic development is to bring lasting maximum utility to consumers, and to meet and comprehensively improve the overall level of social welfare. Consumers face a trade-off between consumption and investment. In time $\mathrm{t}$, the total income of consumers in industry i is $\gamma_{i t} A_{i t}+\omega_{i t} L_{i t}$. At this time, income is used to save to increase assets, in addition to consumption. At moment $\mathrm{t}$, the total income of consumers is $C_{i t}$, and the budget constraints they face can be expressed as: $A_{i t}=\gamma_{i t} A_{i t}+\omega_{i t} L_{i t}-C_{i t}$.

In the industrial economies, the utility maximization problem under the total amount of consumers can be expressed as:

$$
\begin{array}{r}
c_{\mathrm{it}, A_{i t}}^{\max } U_{i}=\int_{0}^{\infty} U\left(C_{i}\right) e^{-p_{i} t} d t \\
\text { s.t. } \quad A_{i t}=\gamma_{i t} A_{i t}+\omega_{i t} L_{i t}-C_{i t} \\
A_{0} \text { is known. }
\end{array}
$$

For each representative consumer, they choose consumption path, capital stock path and labor supply path to maximize efficiency under their own budget constraints, and maximize the total amount to maximize the utility per capital. Therefore, the per capital discount rate is recorded as: 


\subsubsection{Equilibrium solution}

$$
\begin{array}{r}
\beta_{i}=\rho_{i t}-n_{i t} . \\
\max _{\sigma_{i t} a_{i t}} u_{i}=\int_{0}^{\infty} u\left(c_{i}\right) e^{-p_{i} t} d t \\
\text { s.t. } \dot{a}_{i}=\left(\gamma_{i}-n_{i t}\right) a_{i}-C_{i}
\end{array}
$$

According to Xiao Xingzhi,'s (2012) [6]standpoint, this paper determines that the per capital production function of three industries is expressed as $\mathrm{f}\left(k_{i}\right)=A_{i} k_{i}^{a_{i}}(i=1,2,3)$, and the utility function of a single representative consumer is expressed $\mathrm{u}\left(c_{i}\right)=\frac{c_{i}^{1-\sigma}}{1-\sigma}(i=1,2,3)$. It is assumed that the utility function is in the form of CARA, and consumers have a constant preference for relative risk aversion. By substituting the above two models into the producer maximization model and the consumer utility maximization model, the optimal consumption path and the optimal capital accumulation path of each industry are obtained by solving them simultaneously with the Hamilton method.

$$
\left\{\begin{array}{c}
\dot{c}_{i}=\frac{1}{\sigma}\left(A_{i} a_{i} k_{i}^{a_{i}-1}-n_{i}-\beta_{i}\right) \\
\frac{\dot{k}_{i}}{k_{i}}=a_{i} k_{i}^{a_{i}-1}-n_{i}-\frac{c_{i}}{k_{i}}
\end{array}\right.
$$

At the same time, we can also get the steady state of each industry as an economy if the growth rate is zero. That is, the economy converges to this stable state.

$$
\left\{\begin{array}{c}
\left.c_{i}^{*}=\left(\frac{n_{i}+\beta_{i}}{A_{i} a_{i}}\right)^{\frac{1}{a_{i}-1}}\left(\frac{n_{i}+\beta_{i}}{a_{i}}-n_{i}\right)\right) \\
k_{i}^{*}=\left(\frac{n_{i}+\beta_{i}}{A_{i} a_{i}}\right)^{\frac{1}{a_{i}-1}}
\end{array}\right.
$$

\subsubsection{Convergence of the optimal route of economic growth in three industries}

Convergence is a very important concept in economic growth, because the economy can automatically converge to its stable state or stable growth path. Once disturbed, the economy can still return to a stable state or a stable growth path under the long-term trend although temporarily deviated. In this paper, According to Xiao Xingzhi,'s (2012) [6]standpoint, the convergence rate is defined as the first-order Taylor series expansion near the stable state, then the first-order linear differential equations are solved, and two solutions of the convector are obtained. Finally, the convergence rate formula of the optimal path of three-industry economic growth is deduced as follows:

$$
\epsilon_{i}=\frac{1}{2}\left[\left(\rho_{i}-n\right)^{2}+4 \rho_{i} \frac{1-\alpha_{i}}{\sigma_{i}}\left(\frac{\rho_{i}}{\alpha_{i}}-n\right)\right]^{\frac{1}{2}}+\frac{1}{2}\left(\rho_{i}-n\right) \quad i=1,2,3
$$

Then the simulation models of the growth path of industrial capital are as follows:

$$
\log \left[k_{i}(t)\right]=\left(1-e^{-\varepsilon_{i} t}\right) \log \left[k_{t}^{*}(t)\right]+e^{-\varepsilon_{i} t} \log \left[k_{i}(0)\right]
$$

At this time, $k_{i}(0)$ is the initial per capita capital stock of each industrial economy.

The simulation model of output growth path of each industry is as follows:

$$
\log \left[\gamma_{i}(t)\right]=\left(1-e^{-\varepsilon_{i} t}\right) \log \left[\gamma_{t}^{*}(t)\right]+e^{-\varepsilon_{i} t} \log \left[\gamma_{i}(0)\right]
$$

At this time, $\gamma_{i}(0)$ is the per capita output at the beginning of each industry economy.

\subsection{Simulations of the convergence rate of economic growth in the three industries}

Based on the above estimated variables, the formula is substituted. 


$$
\epsilon_{i}=\frac{1}{2}\left[\left(\rho_{i}-n\right)^{2}+4 \rho_{i} \frac{1-\alpha_{i}}{\sigma_{i}}\left(\frac{\rho_{i}}{\alpha_{i}}-n\right)\right]^{\frac{1}{2}}+\frac{1}{2}\left(\rho_{i}-n\right) \quad i=1,2,3
$$

It can be able to calculate the optimal convergence rate of three industrial economic growth in Fuzhou from 1989-2018 years. Then, we compared and analyzed the same trend and difference between the optimal convergence rate and the actual economic growth rate of the three industries in Fuzhou. The comparison results are shown in Table 5 and Figure 1, Figure 2, Figure 3.

Table 1 Comparison of real output growth rate and optimal real output convergence rate of the three industries

(Unit: \%)

\begin{tabular}{|c|c|c|c|c|c|c|}
\hline \multirow{2}{*}{ Year } & \multicolumn{2}{|c|}{ The Primary Industry } & \multicolumn{2}{c|}{ The Secondary Industry } & \multicolumn{2}{c|}{ The Tertiary Industry } \\
\cline { 2 - 7 } & $\begin{array}{c}\text { Real growth } \\
\text { rate }\end{array}$ & $\begin{array}{c}\text { Optimal } \\
\text { convergence rate }\end{array}$ & $\begin{array}{c}\text { Real growth } \\
\text { rate }\end{array}$ & $\begin{array}{c}\text { Optimal } \\
\text { convergence rate }\end{array}$ & $\begin{array}{c}\text { Real growth } \\
\text { rate }\end{array}$ & $\begin{array}{c}\text { Optimal } \\
\text { convergence rate }\end{array}$ \\
\hline 1989 & 10.77 & 8.52 & 6.10 & 10.07 & 17.97 & 4.98 \\
\hline 1990 & 7.51 & 8.44 & -4.64 & 9.80 & 6.18 & 7.82 \\
\hline 1991 & 53.76 & 6.35 & 5.96 & 9.85 & 9.89 & 4.95 \\
\hline 1992 & 23.67 & 8.45 & 12.31 & 6.89 & 24.77 & 2.14 \\
\hline 1993 & 13.08 & 4.91 & 13.53 & 8.19 & 2.79 & 10.37 \\
\hline 1994 & 1.99 & 11.61 & 0.01 & 6.41 & 2.39 & 10.85 \\
\hline 1995 & 0.44 & 16.45 & 0.96 & 8.01 & 9.39 & 8.08 \\
\hline 1996 & 17.16 & 11.47 & 1.48 & 3.76 & 10.42 & 8.45 \\
\hline 1997 & 26.47 & 10.95 & 0.67 & 3.42 & 5.23 & 7.97 \\
\hline 1998 & -11.22 & 12.56 & -1.29 & -1.45 & 11.70 & 12.71 \\
\hline 1999 & -7.33 & 10.01 & -0.73 & 5.81 & 20.31 & 8.02 \\
\hline 2000 & -1.89 & 14.23 & 7.94 & 3.20 & 9.15 & 6.11 \\
\hline 2001 & -8.08 & 32.53 & 1.95 & -0.53 & 10.45 & 15.01 \\
\hline 2002 & 0.64 & -0.03 & -1.24 & -3.16 & 8.63 & 5.77 \\
\hline 2003 & -7.15 & 13.96 & 6.37 & -1.04 & 19.97 & 14.45 \\
\hline 2004 & -8.58 & 5.35 & -0.84 & -2.18 & 13.61 & 12.27 \\
\hline 2005 & -2.25 & 7.61 & 3.88 & 3.40 & 15.74 & 10.95 \\
\hline 2006 & -1.47 & -0.01 & 4.91 & 3.31 & 16.92 & 6.41 \\
\hline 2007 & 0.05 & 4.40 & 7.28 & 4.02 & 15.37 & 5.07 \\
\hline 2008 & -2.26 & 4.56 & 10.03 & 10.01 & 7.54 & 6.32 \\
\hline 2009 & -1.16 & 7.02 & 7.22 & 10.032 & 16.93 & 4.94 \\
\hline 2010 & 3.84 & 9.21 & 11.41 & 3.95 & 22.95 & 4.92 \\
\hline 2011 & 1.83 & 3.95 & 18.71 & 9.91 & 15.31 & 4.92 \\
\hline 2012 & 2.87 & 0.91 & 23.41 & 7.18 & 17.98 & 4.97 \\
\hline 2013 & -0.02 & 5.54 & 7.72 & 7.76 & 17.98 & 4.97 \\
\hline 2014 & -0.75 & 2.43 & 7.19 & 7.71 & 20.43 & 5.78 \\
\hline 2015 & 11.41 & -0.01 & 11.84 & -2.15 & 19.29 & 4.96 \\
\hline 2016 & 5.96 & 3.52 & -0.43 & 3.98 & 12.65 & 5.01 \\
\hline 2017 & 6.49 & 8.53 & 10.39 & 10.07 & 14.34 & 5.01 \\
\hline 2018 & 2.67 & 8.41 & 15.85 & 9.78 & 10.20 & 7.79 \\
\hline & & & & & & \\
\hline
\end{tabular}




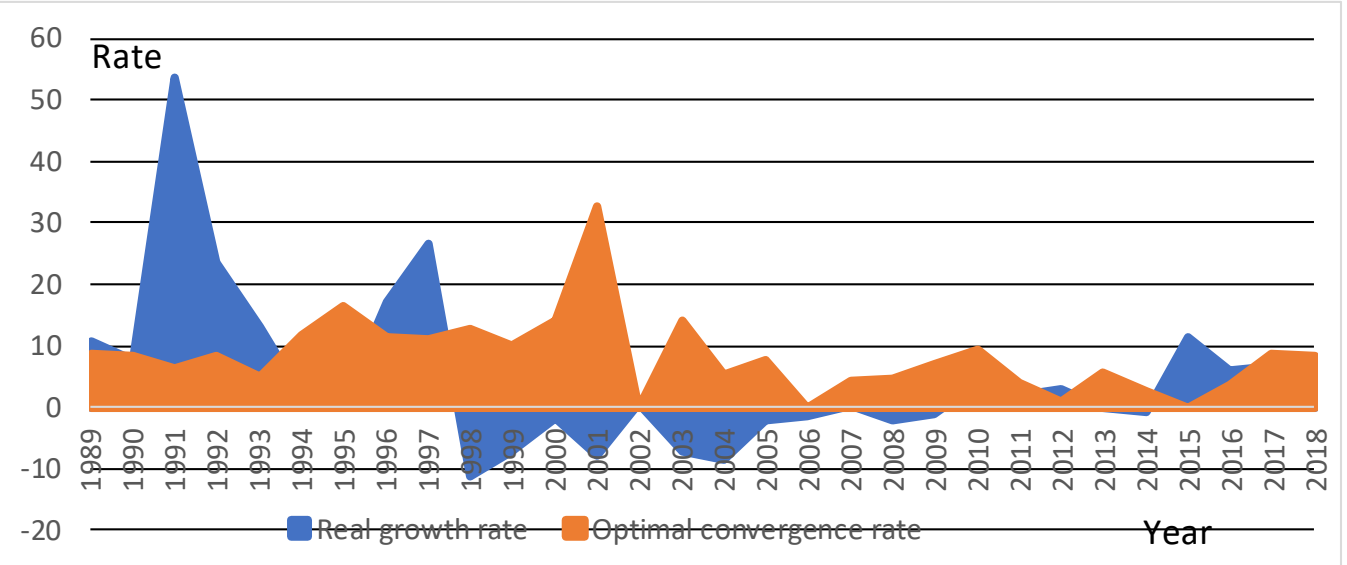

Figure 1 Comparison of real growth rate and optimal convergence rate of the primary industry

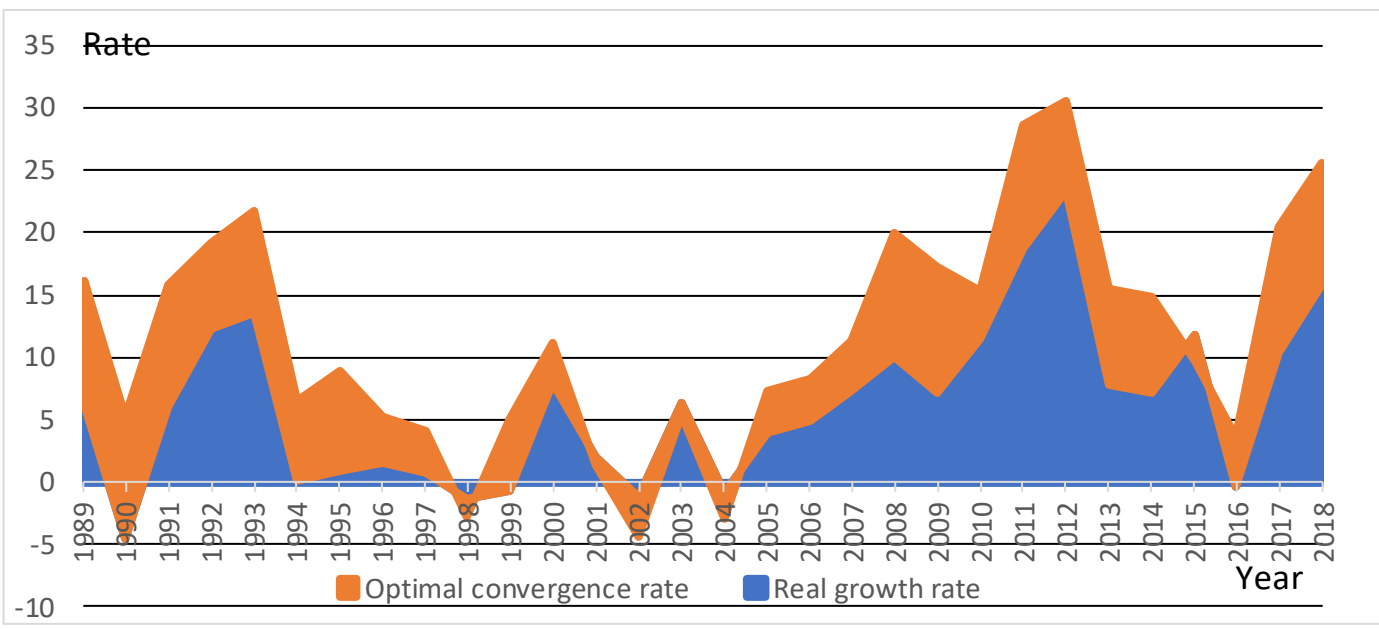

Figure 2 Comparison of real growth rate and optimal convergence rate of the secondary industry

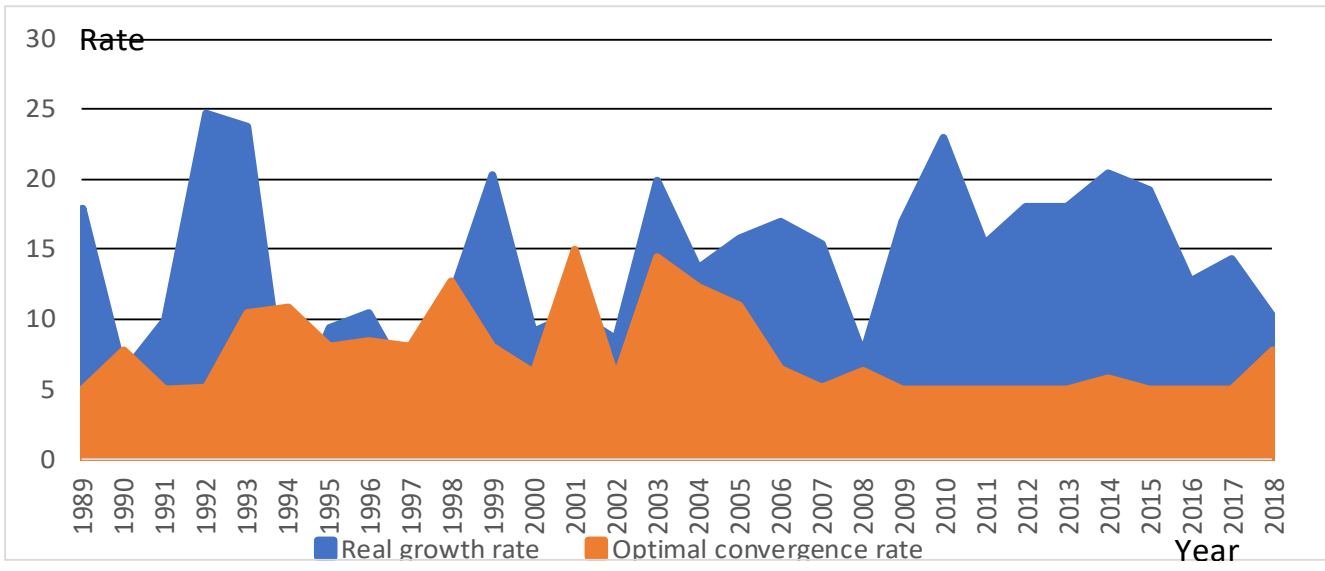

Figure 3 Comparison of real growth rate and optimal convergence rate of the trinary industry

By displaying and synthetic analyzing based on the above charts, we can conclude that it maintained the same trend of the real growth rate and the optimal convergence rate of the three industries in Fuzhou, but there are also great differences and fluctuations in different years.

The real growth rate of the primary industry fluctuated more rapidly in 1989 -2018. In 20002009, it slowed down obviously, and even sustained negative growth for a long time. After 2010, it rebounded slightly and maintained a relatively stable low-speed growth. The optimal convergence rate of the primary industry maintained a stable high value from 1989 to 2000, and the real growth rate tended to approach the optimal convergence rate. The real growth rate and the optimal convergence rate had a more synchronous trend in 2009-2018 with relatively stable low-speed 
growth. It shows that the primary industry was mature and its output value was relatively stable.

It had a good fitting trend of the real growth rate and the optimal convergence rate of the secondary industry in Fuzhou. This shows that the development of the secondary industry was fine and the industrial structure was better. The real growth rate of Fuzhou's secondary industry fluctuated greatly and its level was low from 1999 to 2009. However, the secondary industry has developed rapidly after 2010, such as the rapid growth of real estate industry and the process of rapid development of emerging industries to promote the second industry to take off again.

Unlike the primary and secondary industries, the real growth rate of the tertiary industry in Fuzhou had always maintained a positive high growth rate. In 2007-2013, the real growth rate of the tertiary industry fluctuated greatly, and the growth rate was obviously larger than the optimal convergence rate. It shows that the development of tertiary industry was insufficient and the structure was unreasonable.

Through the research, we used the model to solve the joint goal of maximizing producer's profit and maximizing consumer's cross-term utility. We got the optimal convergence rate of Fuzhou's three industries, and complete the calculation and analysis of the three industries in Fuzhou. This paper calculated the labor elasticity of three industries from using one-year deposit interest rate to express the subjective utility discount rate of consumers and applying Stochastic Frontier Analysis (SFA), which based on the data of output, capital input and labor force of three industries in Fuzhou from 1989 to 2018. Finally, we calculated the optimal convergence rate and compared the real growth rate of the three industries in Fuzhou.

\section{Conclusion}

The results show that it maintained a certain relationship of the same direction of the real growth rate and the optimal convergence rate of the three industries in Fuzhou, and there is also a significant gap between aforesaid those in different periods. It is found that the correlation and the trend of change between them can clearly reflect the adjustment policies of the three industrial structures which began in the early 21st century. During this period, the fluctuation of Fuzhou's economic development speed increased, mainly because the implementation of the socialist market economy system with Chinese characteristics has been fully operational since the 1990s. At the same time, the impact of private enterprises on state-owned and collective-owned enterprises had led to the redistribution of resources in three industries. This also prompted productivity and production level to enter oscillation adjustment period and adaptation period, which is also a microcosm of China's reform process. Since the 21st century, the new economic system has adapted to China's economic environment. The great impetus of coordination and mutual promotion among industries has begun to emerge, which has opened up the 15 years of rapid development of Fuzhou. In addition, as the economic and political center of Fujian Province, Fuzhou has concentrated scarce resources such as labor and capital. Concurrently, the advantages of low capital cost and high quality of labor force also accelerate the development of Fuzhou's three industries, such as hightech industry and financial industry. But it can not be ignored that, as one of the scarce resources, the price of land resources also rises rapidly at the same time, which leads to the high price of real estate and becomes a thorny livelihood problem. In conclusion, the optimal convergence rate of the three industries well describes the development trend of Fuzhou's national economy and the change of industrial structure.

\section{Acknowledgements}

This research was financially supported by the Major Project of Social Science Plan Fund(2017FZA01).

\section{References}

[1] Dasgupta, P. and J. E. Stiglitz, 1980, Industrial Structure and the Nature of Innovative Activity, 
Economic Journal 90, 266-293.

[2] Cohen, W.M. and R.C. Levin, 1989, Empirical Studies of Innovation and Market Structure, in: Schmalensee, R. and R.D. Willig (eds.), Handbook of Industrial Organization, Vol. II, Amsterdam, 1059-1107.

[3] Syrquin, M., 1994, "Structural Transformation and the New Growth Theory", in Pasinetti, L. and Solow, R. M. (Eds.), Economic Growth and the Structure of Long-Term Development, St. Martin Press.

[4] Michael Peneder, 2003, "Industrial Structure and Aggregate Growth", Structural Change and Economic Dynamics, 14, 427-448.

[5] Vittorio Valli and Donatella Saccone, 2009, "Structural Change and Economic Development in China and India", The European Journal of Comparative Economics, 6, 101-129.

[6] Xiao Xingzhi, Peng Yingzhong, Li Shaolin, 2012, China’s Optimal Industrial Structure: The Theoretical Model and Quantitative Calculation, China Economic Quarterly, 4, 135-162. 